\section{Exploring the interrelationship among patterns of service strategy changes and organizational design elements}

\author{
Heiko Gebauer, Thomas Fischer and Elgar Fleisch \\ ITEM-HSG, University of St Gallen, St Gallen, Switzerland
}

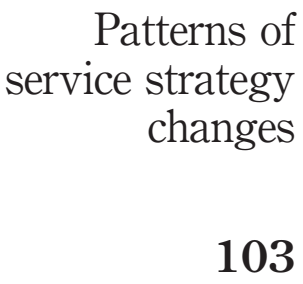

Received 14 September 2008 Revised 24 February 2009,

15 June 2009

Accepted 14 October 2009

\begin{abstract}
Purpose - The purpose of this paper is to explore the patterns of service strategy changes in manufacturing firms and indicates how each pattern is interrelated with modifications in organizational design elements.

Design/methodology/approach - The paper draws on a longitudinal study using a survey of 97 manufacturers of capital goods. In addition, 15 case studies have been conducted. Survey and qualitative data are obtained in 1997, 2001, and 2004.

Findings - The findings highlight four patterns of service strategy changes: from customer service strategy to after-sales service provider, from after-sales service provider to customer-support service provider, from customer-support service provider to development partner, and from customer-support service provider to the outsourcing partner. Evidence of specific alignment between service strategy and organizational design elements is provided.

Research limitations/implications - The main limitation of this paper is the purposive sample. Practical implications - Managers should follow the patterns of service strategy changes by extending the service offerings and modifying the organizational design elements.

Originality/value - Previous studies investigate service strategies and organizational design elements only at a specific time, which leads to a static perspective. This paper offers insights into interrelations among service strategy changes and organizational design elements.
\end{abstract}

Keywords Manufacturing industries, Organizational design, Strategic management, Services, Change management

Paper type Research paper

\title{
Introduction
}

Manufacturers of capital goods rely on services for much of their corporate profits and revenues. This fact applies for well-known firms such as International Business Machines (IBM) and General Electric (GE) as well as small- and medium-sized companies such as Burkhardt Compression. This medium-sized company has manufactured compressors for the last three decades and until the mid-1990s, the value contribution of services was limited to a share of services' revenue and a profit of

The authors would like to thank the Swiss National Science Foundation (www.snf.ch) for sponsoring the research activities; also the Editor and the anonymous reviewers for helpful comments to improve the quality of the paper; and Colleen Murphy for support with the language corrections.

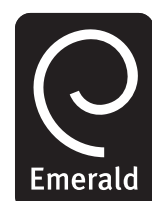

Journal of Service Management

Vol. 21 No. 1,2010 pp. 103-129

(C) Emerald Group Publishing Limited 1757-5818

DOI 10.1108/09564231011025137 
JOSM 21,1

104 less than 10 percent. Recently, services generate about 24 percent of corporate revenue and account for 45 percent of corporate profit.

The increase in value contribution through services is related to changes in the service strategy. Burkhardt Compression changed from augmenting the product offering through customer service to offering services such as spare parts, maintenance and repair for its installed base of compressors. IBM implemented several changes in its service strategy, leading to business consulting offered by IBM Global Services. Interestingly, according to IBM's income statement, the fraction of pretax income attributed to services has dropped from 41 to 37 percent between 2003 and 2007 despite the changes in service strategies. In contrast, GE changed its service strategy from providing services for its air engines, selling the jet engines and selling maintenance services, to selling jet-engine usage. With this new service strategy, GE has grown by 50 percent between 2004 and 2007. Since jet engine and maintenance services are bundled into selling jet-engine usage, the total revenue cannot be attributed to the products or services.

Despite the increasing number of research contributions to service strategies in the manufacturing context, important knowledge gaps remain. First, researchers focus on the static term of service strategy, but there seems to be a steady change in the strategic role of services (Bowen et al., 1989; Neu and Brown, 2008). Davies' (2004) description of service strategies (system integration, operational services, and business consulting) and Gebauer's (2008) service strategies (after-sales service provider, customer-support service provider, outsourcing partner, and development partner), for example, reflect a content view of service strategy and are rather static. They do not fully capture dynamic, process-oriented perspectives on changing from one service strategy to another. It remains unclear whether companies change their service strategy from system integration to business consulting or from operational services to system integration.

Second, Oliva and Kallenberg (2003) present a dynamic perspective on the transition from products to services. It remains unclear, however, whether their four phases of consolidating the service offering, entering the service market for the installed base, moving into process- as well as relationship-oriented services, and taking over the customers' operational processes) correspond with distinct service strategies or with a single service strategy that is translated situationally into different service offerings.

Third, research neglects how service strategy changes are interrelated with necessary modifications in organizational design elements. Despite the contribution describing organizational design elements in the context of service strategies, the frequency of the changes to the organizational structures indicates an absence of robust descriptions about how patterns of service strategy changes are interrelated with modifications in organizational design elements (Davies, 2003; Davies et al., 2007). The missing alignment can cause the "service paradox," where substantial investment in extending the service business leads to higher costs but does not generate the expected higher returns (Gebauer et al., 2005; Neu and Brown, 2008). It remains unclear what modifications are necessary if companies move from providing system integration services to operational services or from operational services to business consulting. The typical modifications suggested in the literature such as separating the service organization from the product, increasing service orientation in corporate 
culture or implementing service development processes (Gebauer et al., 2005; Martin and Horne, 1992; Neu and Brown, 2005, 2008; Oliva and Kallenberg, 2003) are not linked to changes in service strategies.

This study combines the dynamic (process) perspective on changes among service strategies with the content perspective on the conceptualization of service strategies and service offerings. By combining both perspectives, we identify if and how companies move from one service strategy to another in order to find the prevalent patterns of strategic change during the transition process. Furthermore, assuming these patterns depend on contingency factors (Gebauer, 2008; Neu and Brown, 2005, 2008), this study links changes in the service strategy with modifications in organizational design elements. Consequently, this paper attempts to answer the following research question:

$R Q$. What are the interrelationships between patterns of service strategy changes and organizational design elements during manufacturing companies' transition to services?

The answer to this $R Q$ contributes to service research in two different ways. First, we integrate the loosely linked content and dynamic perspectives of service strategies prevalent in the literature and explore patterns of strategic changes among service strategies in manufacturing companies. Second, we link patterns of service strategy changes to modifications in organizational design elements.

This paper draws on a longitudinal study of 97 capital goods manufacturing companies and 15 case studies from a business-to-business context. Data were obtained in 1997, 2001, and 2004. The paper proceeds with a literature review. The research methodology is presented in third and fourth sections describe the results. The paper concludes with a discussion on the research contributions and managerial implications, as well as suggestions for further research.

\section{Literature review}

\section{Content perspective (static perspective) on service strategies}

Early literature on the strategic aspects of services in manufacturing companies considers services to be part of business strategy (Kellogg and Nie, 1995; Bowen, 1990). Customer service, for example, contributes to quality reputation (Morrison and Roth, 1992) through increasing the general quality of interaction between buyer and seller (Parasuraman, 1998; Kyj and Kyj, 1989; Lovelock, 1994). The various manufacturing strategies of marketeers (designers), innovators, idlers, mass customizers and servers differ in their emphasis on services (Miller and Roth, 1994; Frohlich and Dixon, 2001). Marketeers' strategy is oriented towards reliability in the manufacturing process, especially in terms of quality and delivery. The caretakers' strategy is uniquely preoccupied with low price, more so than with all other potential competitive capabilities. The innovators' strategy is characterized by an emphasis on quality and innovation in order to avoid price competition. Mass customizers focus on convergence and flexibility. Idlers are assumed to emphasize the combination of competitive capabilities aggressively. Servers are clearly associated with strong after-sales service support for customers (Frohlich and Dixon, 2001). After-sales services are of average strategic importance to mass customizers, marketeers, caretakers, and innovators. Idlers place only a low emphasis on services as a competitive priority (Miller and Roth, 1994; Frohlich and Dixon, 2001).

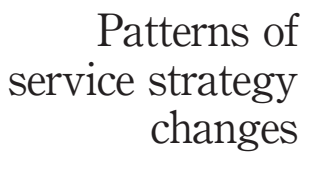

105 
JOSM 21,1
Researchers with a service management background approach service strategies through types of service offerings. Mathieu (2001b) describes three types of services: customer service, product services and services as a product. Customer service addresses the general quality of interactions between seller and customer, whereas product services ensure the proper functioning of a product. Service products are considered independent of the company's product (Mathieu, 2001b). Davies (2004) suggests directions for moving towards offering high-value solutions (integrating systems, providing operational services, and offering business consulting) that are linked directly to service offerings. Systems integration includes design services that integrate components into a functioning system. Operational services include the provision and responsibility for operating and maintaining products (Davies, 2004; Davies et al., 2007). Business consulting is a service that advises customers on designing, financing, purchasing, maintaining, and operating capital goods (Davies, 2004; Kotler, 1994; Davies et al., 2007).

Gebauer (2008) combines the approaches of service strategies as part of the business strategy with services strategies as different types of service offerings. The author identifies four different service strategies:

(1) after-sales service strategy;

(2) customer-support service strategy;

(3) development partner; and

(4) outsourcing partner.

Each of these four strategies is based on a specific set of service offerings. After-sales service providers concentrate on basic services for the installed base, whereas customer-support services entail mainly maintenance services (Kotler, 1994; Oliva and Kallenberg, 2003). Development partners provide professional R\&D-oriented services such as development, design and construction services. Outsourcing partners offer services where suppliers take over the responsibility for customer processes. By combining service strategy with business strategy, the after-sales service providers and outsourcing partners conform well to the cost leadership strategy. In contrast, the provision of customer-support services and the strategic position of the development partner require differentiation strategies (Gebauer, 2008).

Dynamic perspective on the transition from products to services

Researchers who concentrate on the dynamic perspective of the transition from products to services focus on changes in the total offering. Vandermerwe and Rada (1988), for example, view this transition as a process of "servitization." This process contains three stages:

(1) the company sells goods;

(2) goods and services are combined in offerings; and

(3) offerings are complex bundles of goods, services, information, support, and self-service elements.

According to Martin and Horne (1992) and Kotler (1994), the shift in total offerings follows a specific pattern beginning with goods only, then goods- and service-dominant total offerings, and finally services only. The concept of total offering has been 
extended towards a system of service layers around the product. Services are expected to change their role from being the layers around the product to being the center of the layers (Belz et al., 1997; Gummesson, 1994).

Oliva and Kallenberg (2003) propose that the transition starts with consolidating the existing service offering. It proceeds with entering the market for the installed bases through offering basic after-sales services. Basic after-sales services are associated with repair, trouble-shooting, product-oriented training, help desk and inspection/diagnosis. The strategic goal of these services is to ensure the proper functioning of the product and to yield potential service revenues from the installed base (Mathieu, 2001a; Wise and Baumgartner, 1999; Oliva and Kallenberg, 2003). The process continues by expanding the service offering towards process- and relationship-oriented services. On one hand, these process- and relationship-oriented services focus on improving the effectiveness and efficiency of the product within the customer process (Mathieu, 2001a; Oliva and Kallenberg, 2003). On the other hand, these services support manufacturing companies in increasing the utility of service capacities by changing the focus of the service offered - from unscheduled to scheduled service interventions. The transition process ends with taking over customer processes by offering operational services (Oliva and Kallenberg, 2003).

\section{Organizational design elements}

The service strategies previously outlined depend on contingency factors. Maintaining the organizational performance during service strategy changes requires modifications in organizational design elements (Gebauer, 2008; Neu and Brown, $2005,2008)$. In the context of organizational design, the literature describes a range of dimensions such as structure, coordination, culture, and power that allow comparisons of organizations (Homburg et al., 2000). Lately, in the context of service strategies in manufacturing companies, the contingency factors include elements such as human resources, processes, structure, culture, and measurement and rewards (Matthyssens and Vandendempt, 1998; Neu and Brown, 2005; Oliva and Kallenberg, 2003; Gebauer et al., 2005; Johnstone et al., 2008). Service strategy changes require an alignment among these organizational design elements. By entering the market for the installed base, companies align their organizational structure by separating the service business from the product business (Oliva and Kallenberg, 2003). Neu and Brown (2005) argue that the development of business-to-business services corresponds with the modifications in human resources, structure, measurement and performance, and processes. Typical modifications include adapting front line roles to cope with the complex market, hiring for behavioral competencies, technical expertise and attitude, integrating business unit responsibilities, decentralization, and adapting the management financial incentive system (Neu and Brown, 2005). Homburg et al. (2003) argue that increasing the service orientation in the business strategy requires an increase in the service orientation of the corporate culture and human resource management. Martin and Horne (1992) consider the recognition of service potential and service development as positively associated with the success of an organizational move from a product- to a service-centric total offering. Mathieu (2001b) argues that service strategies undertaken by manufacturing companies have an impact on three different levels of organizational intensity (strategic, tactical, and cultural). These are

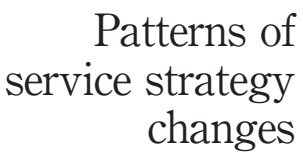

107 
JOSM 21,1

108

few examples of organizational design elements corresponding with the patterns of service strategy changes.

\section{Conceptual framework}

By using the existing literature, we develop a conceptual framework that combines service strategies with modifications in organizational design elements. Service strategies of manufacturing companies focus on realized strategies. This means that service strategies are viewed as companies' existing strategic priority in the service offering rather than in the intended offering (Mintzberg and Quinn, 1988). As shown in Figure 1, potential service offerings include customer service, basic services for the installed base, maintenance services, R\&D-oriented services and outsourcing

\begin{tabular}{|c|c|}
\hline Service strategies (t1) & \multirow[b]{2}{*}{$\begin{array}{l}\text { Strategic importance of } \\
\text { service categories } \\
\text { - Customer service } \\
\text { - Basic services for the } \\
\text { installed base } \\
\text { - Maintenance services } \\
\text { - R\&D-oriented services } \\
\text { - Outsourcing } \\
\text { (operational) services }\end{array}$} \\
\hline $\begin{array}{l}\text { - Customer service } \\
\text { - Basic services for the } \\
\text { installed base } \\
\text { - Maintenance services } \\
\text { - R\&D-oriented services } \\
\text { - Outsourcing } \\
\text { (operational) services }\end{array}$ & \\
\hline \multicolumn{2}{|c|}{ 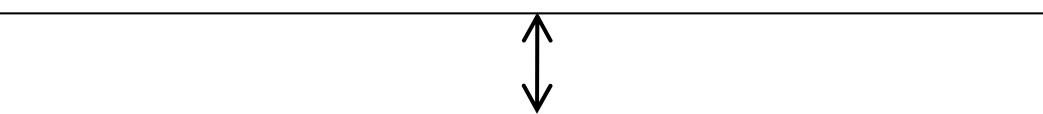 } \\
\hline \multicolumn{2}{|c|}{ Modification of organizational design elements } \\
\hline $\begin{array}{l}\text { Corporate culture } \\
\text { - Corporate values } \\
\text { - Employee behavior }\end{array}$ & $\begin{array}{l}\text { Human resource management } \\
\text { - Personnel recruitment } \\
\text { - Personnel training } \\
\text { - Personnel assessment/ } \\
\text { compensation }\end{array}$ \\
\hline $\begin{array}{l}\text { Organizational structure } \\
\text { - Organizational distinctiveness } \\
\text { between products and services } \\
\text { - Proximity of the service } \\
\text { organization to customers }\end{array}$ & $\begin{array}{l}\text { Service development } \\
\text { - Formality of the service } \\
\text { development process } \\
\text { - Customer involvement in the } \\
\text { service development process }\end{array}$ \\
\hline
\end{tabular}

Figure 1.

Conceptual framework 
(operational) services (Kotler, 1994; Belz et al., 1997; Mathieu, 2001b; Oliva and Kallenberg, 2003; Davies, 2004; Neu and Brown, 2005).

Considering the research on organizational design in the context of manufacturing companies moving towards services (Simon, 1993; Belz et al., 1997; Lay, 1998; Galbraith, 2002; Martin and Horne, 1992; Neu and Brown, 2005), we believe that the decisions about the service orientation of corporate culture, human resources, organizational structure, and service development are major decisions about how manufacturing companies align their organizational design with service strategy changes.

In our framework, corporate culture involves two organizational elements, namely, corporate values and employee behavior. The two elements capture the value of services within companies and the degree to which employees behave in a service-oriented way. Human resource management involves three elements: personnel recruitment, personnel training and personnel assessment/compensation (Homburg et al., 2003). The organizational structure captures two elements. The first element refers to the organizational distinctiveness between products and services, which represents the degree to which the service business unit is established as a distinct business unit with the corresponding profit-and-loss responsibility (Noch, 1995; Oliva and Kallenberg, 2003). The second element covers the proximity of the service organization to customers, that is, the extent to which external customers are aware of the service organization and can identify appropriate points of contact (Matthyssens and Vandendempt, 1998). The service development includes two elements, namely, the formality of the service development process and customer involvement in the service development process (Martin and Horne, 1992). As shown in Figure 1, we include a total of five service categories/strategies and nine organizational design elements in our conceptual framework. Figure 1 shows that changing from one service strategy to another service strategy depends on modifications in organizational design factors.

\section{Research methodology}

Given the research objective of analyzing the interrelationship between patterns of service strategy changes and modifications in organizational design elements, a longitudinal study using survey data and case studies was deemed appropriate.

\section{Empirical quantitative research approach}

Data sample and collection. The empirical evidence was obtained from 1997, 2001, and 2004 surveys using semi-structured questionnaires. A degree of "purposive sampling" was employed in the surveys (Patton, 1990). Selection criteria for the purposive sampling were based on two dimensions. First, to identify successful service strategy changes, we concentrated on companies that demonstrated outstanding performance (high share of service revenues to total revenue, service profitability, and overall company performance, such as average return on sales over the last three years and average return on sales in comparison to industry average). As a second dimension, we focused on variety and diversity across control variables such as industry, product type, company size and legal entity (strategic business unit (SBU) or entire company). Our intension was to achieve a wide variation range rather than statistical representativeness. The diversity in these variables is highlighted in Table I, which presents the descriptive statistics characterizing the participating manufacturing companies. As illustrated in Table I, all participating companies are from the

\section{Patterns of service strategy changes}

109 


\section{JOSM 21,1}

Industry mix ${ }^{\mathrm{a}}(\%)$

Machinery

Equipment

Measurement instruments $\quad 24.7$

$\begin{array}{ll}\text { Electronics } & 14.4\end{array}$

\section{0}

Others

11.4

Unit of analysis (\%)

$\mathrm{SBU}^{\mathrm{b}}$

Entire company

Overall performance

Annual sales revenue (median)

1997 - €150 million

2001 - €220 million

Net profit (mean percentage of sales)

2004 - €250 million

$1997-7.6 \%$

$2001-6.7 \%$

Product mix (\%)

$2004-7.3 \%$

Production material/components 33.5

Finished products

44.8

Engineering projects

13.6

Others

Number of employees category (size) (\%)

Less than 250 employees

11.5

250-499 employees

22.7

500-999 employees

14.4

1,000-2,499 employees

27.8

More than 5,000 employees $\quad 13.6$

Regions (\%)

Europe

64.6

$\begin{array}{lr}\text { North America } & 30.7\end{array}$

Asia

Notes: annless otherwise indicated, "\%" refers to the percent of the sample respondents; ${ }^{b}$ we defined a SBU as a relatively autonomous unit with the management of the SBU having control of at least three of the following functions: marketing, sales, manufacturing, R\&D, accounting/finance, and human resources (Homburg et al., 1999). An analysis was performed to determine whether there were any significant differences among the various groups of respondents. No statistical differences could be observed. A comparison of financial and market performance of the respondents with aggregate

Table I.

Respondent profile statistics industry data suggests a non response bias. Respondents were more likely to be market share leaders and financially more successful. However, this corresponds with the nature of "purposive sampling," that is, to obtain data on organizations demonstrating outstanding performance

business-to-business sector. Major manufacturing industries are represented with a roughly equal share in the sample. This also holds true for the three product types, the number of employees and the legal entity (SBU or entire company).

Contact data of firms were acquired from a commercial data base provider. Altogether, about 500 firms were contacted in each survey. The numbers of respondents vary between 107 and 141 companies, with response rates ranging from 24 to 29 percent. The data analyzed in the present paper come from 97 companies that participated in all three surveys. The corrected response rate for the 97 companies was on average 19 percent. 
Because of concerns expressed in earlier research about the use of key informants (Phillips, 1981), respondents were contacted personally to verify their knowledge about the subject being studied. The key respondents of our survey were chief executive officers (CEOs), service managers or sales managers. Additionally, the quality of the information (Kumar et al., 1993) was assessed through three questions about how long the respondents had worked at the company, the respondents' knowledge about the service business and their work experience with the service strategies at their companies.

Measurement development and validation. The operationalization of service strategies draws either on strategic priorities, as found in traditional strategic management literature, or on the service offerings associated with different service strategies (Gebauer, 2008; Frohlich and Dixon, 2001). Considering our conceptualization of service strategies, we operationalize service strategies consistently through various dimensions of service offerings. In the context of retail businesses, Homburg et al. (2002) use:

(1) number of services offered;

(2) how many customers these services are offered to (broadness); and

(3) how strongly these services are emphasized (promoted) in order to measure the service orientation of a business strategy.

Two of these three dimensions, (1) number of services and (3) emphasis on services, have been used to measure the service orientation of the business strategy in industrial marketing companies (Homburg et al., 2002, 2003). Both types of operationalization have been reused previously with reliable results (Gebauer, 2008; Antioco et al., 2008).

In view of this background, the operationalization of service strategies focused on the strategic importance of service categories. Three dimensions are considered to entail the formative measurement of the strategic importance of each service category:

(1) the number of services offered in one service category;

(2) the relative number of customers using one service category; and

(3) the intensity of promoting one service category.

Formative measures involve the construction of an index, rather than a scale (Bollen and Lennox, 1991). Thus, an exploratory factor analysis for identifying the dimensionality of constructs cannot be applied. Instead, we applied the procedure subsequently described (Antioco et al., 2008).

In the present context, a certain number of services are classified into service categories. In 1997, three service categories were included in the questionnaire, namely: customer service, basic services for the installed base, and maintenance services. These service categories reflect the literature at that time (Belz et al., 1997; Mathe and Shapiro, 1993; Simon, 1992; Boyt and Harvey, 1997). The list of customer services captures five services that are measured on a dichotomous scale (with " $0=$ not offered" and " 1 = offered") indicating whether or not a service was offered (Homburg et al., 2003). The number of services in the customer service category is calculated by the sum of services offered. A similar procedure is used to measure the number of basic services for the installed base and the number of maintenance services. Again, the list includes five services for each service category. The specific services are listed in Table II.

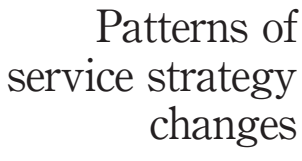

111 
JOSM

21,1

112

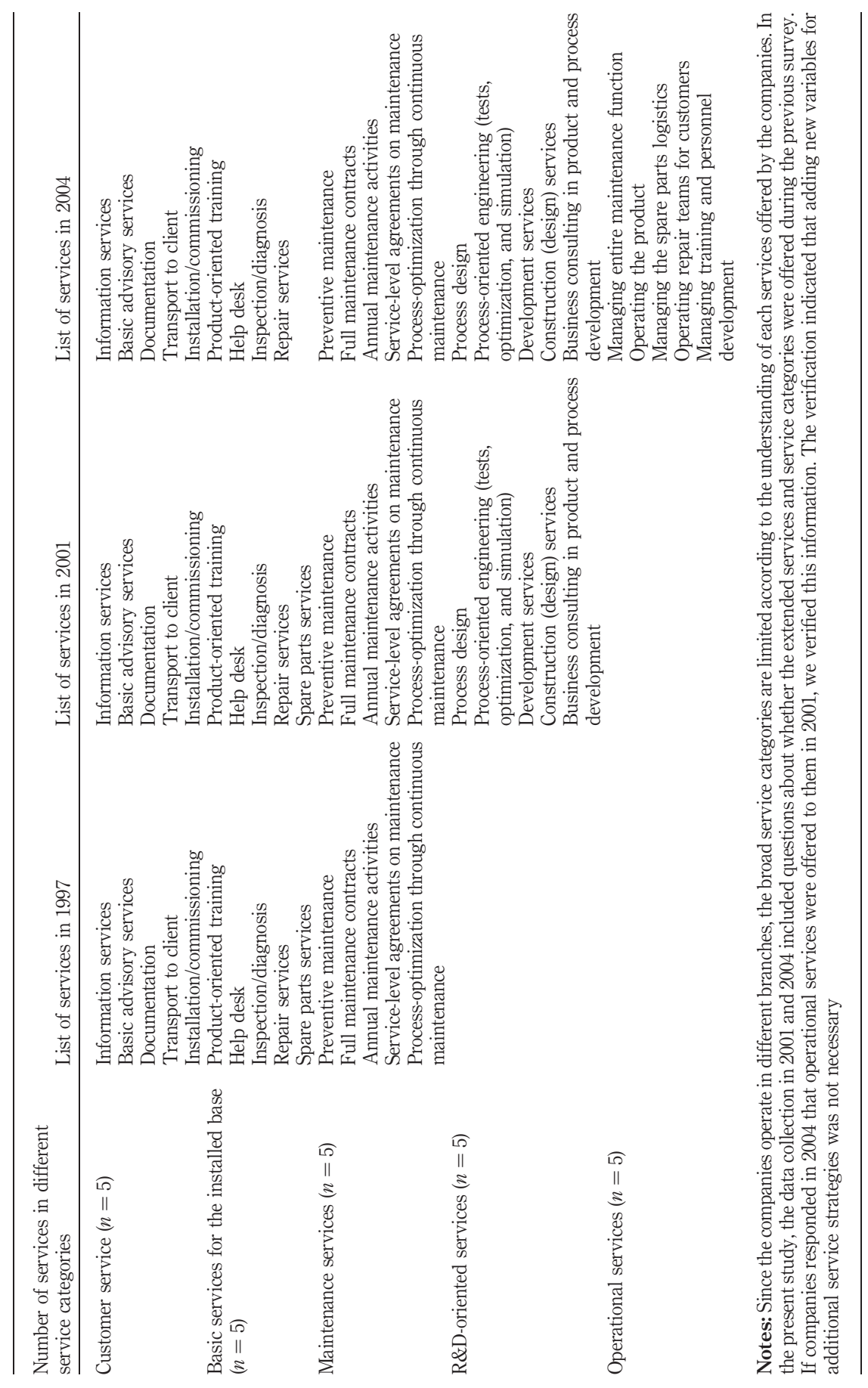

Table II.

Measurement of the number of services for each data inquiry 
Reflecting progress in the literature, additional service categories were integrated into the second and third survey (Wise and Baumgartner, 1999; Oliva and Kallenberg, 2003; Davies, 2004; Schuh et al., 2004). In 2001, customer service, basic services for the installed base, maintenance services and R\&D-oriented services were integrated into the questionnaire. There were five services in each category. The following five service categories were used in 2004: customer service, basic services for the installed base, maintenance services, R\&D-oriented services and operational services. Again, there were five services in each category.

The relative number of customers using and/or demanding each service category is scored on a five-point Likert-type scale with anchors $1=$ "to no customers" and $5=$ "to all customers." Similarly, the intensity of promoting one service category is measured on a five-point Likert-type scale with anchors $1=$ "not at all" and $5=$ "very actively" (Homburg et al., 2003). As previously explained, the number of services in the service category is calculated by the sum of the services offered. Since the number of services is additive (e.g. 0-5 for customer service strategy), this number was also converted to a five-point scale. The strategic importance of one service category is then calculated as a mean of all three corresponding items. Since our analysis does not include any dependent variable for the service categories, we must assume equal weights for the three formative indicators.

Although the analysis is longitudinal with observations from 1997, 2001, and 2004, a different and more limited questionnaire was administered in 1997. One could therefore argue that we did not know whether the firms involved offered some of the higher level services in 1997, whereas we knew these services were offered in the later years. This lack of information might create a problem in terms of understanding the evolution of the strategies. In the present study, the data collection in 2001 and 2004 included questions about whether the extended services and service categories were offered during the previous survey. If companies responded in 2004 that operational services were offered to them in 2001, we verified this information. The verification indicated that adding new variables for additional service strategies was not necessary. The respondents did not claim that additional services were offered during the previous surveys. In this case, there is a low risk that measures computed for each year and consequent allocations to different clusters from one period to another, might not be comparable.

The developed measures for service strategies are indexes composed through formative scales. Four aspects are critical to the successful construction of indexes with formative indicators:

(1) content specification;

(2) indicator specification;

(3) indicator collinearity; and

(4) external validity (Diamantopoulos and Winklhofer, 2001).

To achieve sufficient content specification of service strategy, three dimensions were considered to capture the major facets of service strategies:

(1) the number of services offered;

(2) number of customers demanding one service category; and

(3) intensity of promoting one service category. 
JOSM 21,1

114

Critical for the design of valid indexes with formative indicators is the indicator specification. The indicators must capture the entire scope of the service strategies, as previously described. The number of customers demanding one service category and the intensity of promoting one service category can be interpreted as capturing most probably the entire scope of a service strategy. The number of services is more critical, but we assume that the five services reflect the key services in each of the five service categories (Bowen, 1990; Belz et al., 1997; Mathe and Shapiro, 1993; Simon, 1992; Boyt and Harvey, 1997; Mathieu, 2001b; Oliva and Kallenberg, 2003; Vandermerwe and Rada, 1988; Kumar et al., 2004). As a result, the operationalization of service strategies through number of services offered in one service category, the relative number of customers using and/or demanding each service category and the intensity of promoting one service category provides sufficient content and indicator specification.

Indicator collinearity was assessed by obtaining the variance inflation factor. None of the 15 indicators (three indicators for each service category) revealed serious multicollinearity problems because the maximum variance inflation factor came to 2.343, which is under the common cut-off threshold of ten (Diamantopoulos and Winklhofer, 2001). Therefore, the index for each service category retained the three initial indicators. Whereas, the first three determinants for successful construction of indexes were assessed in the present study, we could not estimate external validity because there were no reflective indicators for the service categories included in the survey. Nevertheless, we will return to this issue in the section on limitations and future research opportunities.

Data analysis. Data analysis includes cluster analysis and cross-tabulation. Cluster analysis, which has been used frequently in strategic management research, was employed to identify the service strategy types from respondent profiles of service categories (Miller and Roth, 1994; Frohlich and Dixon, 2001). The indexes on the strategic importance of service categories were used as input for the cluster analysis. Considering the literature on possible limits to the quality of cluster analysis (Ketchen and Shook, 1996; Punj and Stewart, 1983), a two-stage procedure was applied to ensure confidence in the number of clusters. At the first stage, a hierarchical algorithm was used to define the number of clusters. At the second stage, the number of clusters served as the starting point for a subsequent, nonhierarchical ( $K$-means) cluster analysis. This means that the initial number of clusters in $K$-means cluster analysis was verified with the aid of a hierarchical cluster analysis. The hierarchical cluster analysis was conducted by changing the agglomeration coefficient and observing breaks in the dendogram. Changing the agglomeration coefficient and observing breaks in the dendogram were used to ensure the reliability of the derived number of clusters for the $K$-means cluster analysis (Punj and Stewart, 1983).

The $K$-means cluster analysis uses Euclidean distance. Initial cluster centers are chosen randomly in a first pass of the data and then each additional iteration groups' observations are chosen based on the nearest Euclidean distance to the mean of the cluster. The algorithm seeks to minimize the within-cluster variance and maximize the variability among clusters in an analysis of variance (ANOVA)-like fashion. The process continues until the cluster means do not shift more than a given cut-off value or until the iteration limit is reached (Punj and Stewart, 1983; Ketchen and Shook, 1996).

The resulting cluster memberships obtained through the $K$-mean cluster analysis are positioned in cross-tabulation, in which two different years are positioned on the 
horizontal and vertical axis. Cross-tabulation is employed in order to understand how companies move from one service strategy to another.

Research approach for case study research

Similar to Neu and Brown (2008), we argue that case study research is an appropriate methodology since little academic research has been published about the interrelationship between service strategy changes and organizational design elements. Our $R Q$ is a "what" question exploring what are the interrelationships between patterns of service strategy changes and organizational design elements during manufacturing companies' transition to services? This question is well suited for case research (Yin, 1994). Our approach does not primarily take a grounded theory approach (Strauss, 1987), but concentrates on coding and statistically analyzing data in order to develop supporting propositions for the interrelationship between service strategy changes and organizational design elements.

Data sample. The qualitative research approach is based on 15 case studies. Similar to the survey data, the unit of analysis for the qualitative research approach was SBU or entire company. In the choice of case study, a purposive sampling strategy was used (Eisenhardt, 1989). The case studies were selected to optimally contribute to the analysis of the interrelationships between service strategy changes and organizational design elements. Immediately after each survey in 1997, 2001, and 2004, therefore, we identified participants following dominant patterns of service strategy changes and selected five companies that had above average success in their service strategy changes. In 2001, for example, one of the five selected companies was Ericsson Operating Systems - a manufacturer and service provider for communication network infrastructure. Between 1997 and 2001, Ericsson Operating System changed their service strategy from providing services for their installed network infrastructure to outsourcing the operation and maintenance of the communication network infrastructure for key customers such as Telefonica, Vodafone, Deutsche Telekom, or Orange. Deutz, a manufacturer of diesel engines for ships and trucks, was one of the five selected companies in 1997. Deutz succeeded in changing its service strategy from simply using products to selling services such as repair, maintenance and spare parts for ensuring the proper functioning of their installed diesel engines. Because of data confidentiality, the findings do not include the real names of the participating companies.

Data collection. Each of the 15 selected companies was visited by the research team for one day. A site visit protocol consisting of description of data collection procedures and interview guides was developed to guide our research and strengthen reliability (Yin, 1994). During each site visit, we interviewed between three and six informants. From all 15 case studies, 66 informants were interviewed. Potential informants were identified through a contact person such as the CEO or the head of the service business. The contact persons referred to a variety of functions that were either directly responsible for designing key organizational factors or had insight into service strategy changes. Typical functions were product sales, service sales, product management, logistics, controlling, and human resources. Informants were contacted in advance by phone to verify their agreement to participate.

During the interviews, the informants were asked to give a detailed account of their experiences in attempting to link the service strategy changes and modifications of

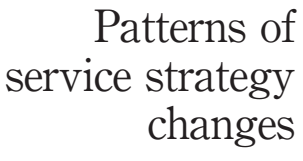

115 
JOSM 21,1

116 organizational design elements. The subjects provided illustrations about how patterns in service strategy changes correspond with modifications in the organizational design elements. The interviews were semi-structured around the previously explained conceptual framework. The semi-structured interview guide was designed to collect data on the service strategy changes and the organizational design elements, as well as providing flexibility to capture additional insights. The interviewee was asked to describe the most important modifications in the organizational design elements during service strategy changes. In 1997, when no prior data were available to conclude on patterns of change for the design of the interview guide, the interviewees were asked to tell stories about their experiences with strategy changes during service business development and corresponding organizational modifications. Consistent with the narrative approach (Miles and Huberman, 1994), follow-up questions were used to explore goals and factors driving the modifications, as well as key challenges from implementing the modifications. At the end of each interview, informants were asked for additional comments and for their assessment of the relative importance of the modifications of the organizational design elements. Additional organizational factors therefore emerged inductively from the fieldwork. Key insights and follow-up questions for future interviews were recorded on the visiting protocol subsequent to each interview (Miles and Huberman, 1994).

Since informants often used different terminology for the same modification in the organizational design element, we developed a transcription to cover a variety of words and phrases before coding all primary and secondary data provided during the interviews in qualitative software research (QSR) nonnumerical unstructured data indexing searching and theorizing software (NVivo 7.0(C) (Strauss and Corbin, 1998). Individual interview transcripts were reviewed by each informant to strengthen construct validity (Eisenhardt, 1989). The reviews often led informants to provide more detailed background information. By allowing all informants to review their interviews, we were able to eliminate some of the bias normally associated with retrospective interviews.

Based on the transcripts of the interviews, we wrote a draft summary on the interrelationships between patterns of service strategy changes and modifications in organizational design elements for each company. Before sending the summary to our contact person, we also inserted follow-up questions to clarify and extend the content. The contact persons reviewed the case summaries, identified gaps in the analysis and suggested additional data collection. Our contact person's perception of the case study was discussed during a follow-up phone conference. The case reports were typically 25-30 pages in length. Each final case report was confirmed by the contact person to validate key findings. The final case studies in each year $(1997,2001$, and 2004) were compiled into an entire report for each year. These three reports include each case study within the corresponding year and small summaries across the five cases. To further enhance validity and reliability, these entire reports were again reviewed by external industry experts, researchers, and contact persons from the investigated companies.

Data analysis. To assure reliability and validity of the data analysis, manual and computer-aided content analyses were used, based on the formerly mentioned QSR procedure, to approach the case studies. The importance of the nine organizational design elements, for example, was calculated by dividing the number of sentences 
referring to one element by the total number of sentences for all elements. The within-case analysis of each service strategy change represented the first step of our data analysis. The idea was to become familiar with each service strategy change as a stand-alone entity. In addition, we assumed that this procedure would help us become familiar with each case that, in turn, accelerates the cross-case comparison. The within-case study analysis allowed the unique modification of organizational design elements in each case to emerge before we transferred findings during the cross-case analysis (Eisenhardt, 1989).

Closely coupled with the within-case analysis is the cross-case analysis. By doing a cross-case search, we used the organizational design elements described either in the conceptual framework or in the within-case analysis. The cross-case analysis contained two different steps. In the first step, we looked for similarities and differences in the importance of modifying the organizational design elements across all case studies of one pattern of service change. We selected pairs of service strategies and then listed the similarities and differences between each pair. This tactic forced us to look for subtle similarities and differences among case studies on the same service strategy change. Our assumption was that this analysis leads to similarities for each pattern of service strategy change. In the second step, the cross-case analysis focused on comparing similarities and differences across patterns of service strategy changes. Again, we selected pairs of service strategies and listed the similarities and differences between each pair. We assumed to find specific differences in the modification of organizational design elements among the patterns of service strategy changes.

\section{Results}

Results of the empirical quantitative study

Service strategies in 1997, 2001, and 2004. By using the index for the strategic importance of customer service, basic service for the installed base, and maintenance services on data for 1997 as input, the cluster analysis yields two different service strategies. As illustrated in the corresponding ANOVA table, customer and basic services for the installed base discriminate between both clusters, whereas maintenances service does not. The cluster analysis leads to two service strategies: customer service and after-sales service providers. The first cluster consists of 60 members and focuses on customer service to augment the product offering. It is consistent with the argument that customer services enhance product quality and quality reputation by increasing the general quality of interaction between buyer and seller (Mathieu, 2001b; Morrison and Roth, 1992; Parasuraman, 1998; Kyj and Kyj, 1989; Lovelock, 1994). Compared to the second cluster, the first cluster means are lower (Table III). The second cluster is interpreted as an after-sales service strategy, consisting of product offerings with a few customer services as add-ons to the products. The second cluster is most similar to both the notion of product services and description of entering the service market for the installed base (Mathieu, 2001b; Oliva and Kallenberg, 2003). The cluster is understood as an after-sales service strategy. As illustrated in Table III, this cluster also places a medium strategic importance on customer service.

In 2001, the cluster analysis produced three different service strategies by using the index on the strategic importance of customer service, basic service for the installed base, maintenance services and R\&D-oriented services. The clusters are discriminated 
JOSM

21,1

\section{8}

Table III.

ANOVA tests associated with cluster analysis and cluster means of

discriminating variables

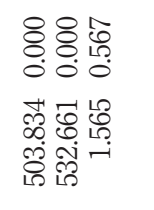

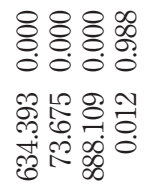

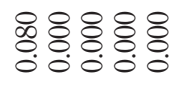

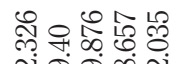

ง

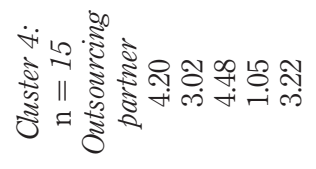

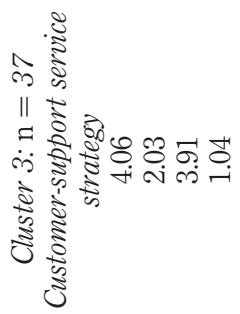

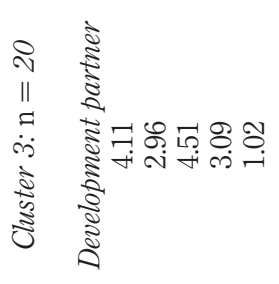

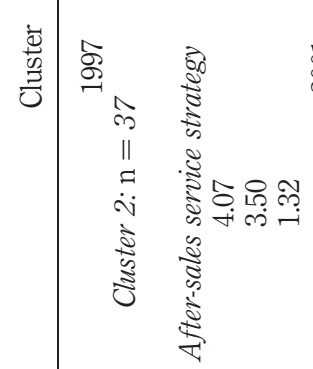
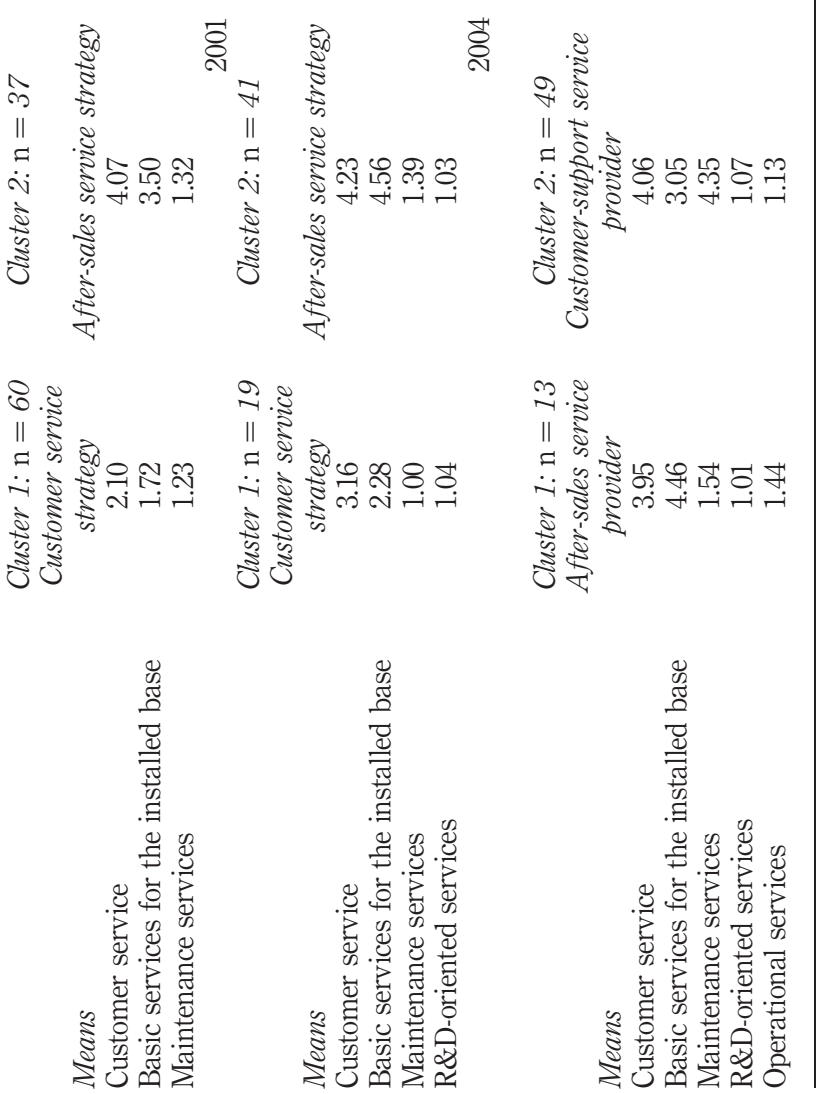
by three of the four service categories. These are customer service, basic service for the installed base and maintenance service. As illustrated in Table III, the R\&D-oriented services do not discriminate among these three clusters and remain on a relatively low level for strategic importance. The first cluster is similar to the indicated customer service strategy of 1997. It contains 33 members. The second service strategy still can be understood as providing after-sales services because of the high level of importance on various basic services for the installed base. Compared to Cluster 3 , this service strategy relating to after-sales service puts little strategic importance on maintenance services. In the third cluster, maintenance services are of high importance, whereas the emphasis on basic services for the installed base is low. Cluster 3 consists of 37 members and involves manufacturing companies following a customer-support service strategy. In contrast to the goal of after-sales service providers simply ensuring proper functioning, Cluster 3 (customer-support service provider) concentrates on improving the effectiveness and efficiency of the product within the customer process.

Finally, the results of the cluster using the five indexes for customer service, basic services for the installed base, maintenance services, R\&D-oriented services and operational services indicated four different service strategies in 2004. Interestingly, customer services (e.g. information service, payment services, and so on) that were established as a discriminating factor in the previous two data inquiries do not discriminate across the clusters at the 5 percent level of significance. This result suggests that most firms across all service strategies have a similar orientation towards customer service. In contrast to the 2001 analysis, four service strategy clusters could be identified. Cluster 1 reflects the after-sales service strategy and consists of 13 members. Cluster 2 has the highest number of members with 49 . Similar to the 2001 analysis, this cluster can be interpreted as firms pursuing a customer-support service strategy. Cluster 3 with its 20 members, places the highest emphasis on R\&D-oriented services, compared to Clusters 1, 2, and 4. The emphasis on maintenance services is similar to Cluster 2. Basic services for the installed base and operational services are of medium to low importance for Cluster 3. Cluster 4 is interpreted as the outsourcing partner and has 15 members. It achieves the highest level of operational (outsourcing) services. In terms of basic services for the installed base and maintenance services, the means are at a medium level. R\&D services are of only marginal importance.

Patterns of changes in service strategies. The patterns of change in service strategies are explored through cross-tabulation. Table IV shows that capital-goods manufacturers changed their service strategy over time: 80.4 percent (78 out of 97) during 1997-2001 and 83.5 percent (81 out of 97) during 2001-2004.

The data reveal four patterns of service strategy change. The first pattern describes the strategic change from customer service strategy to after-sales service provider strategy. Firms relying more on the customer service strategy are moving towards the provision of after-sales services (41 of 60 between 1997 and 2001, and 13 of 19 between 2001 and 2004). The second pattern captures the strategic movement from after-sales service providers towards customer-support service providers (37 of 37 between 1997 and 2001, and 31 out of 41 between 2001 and 2004). None of the after-sales service providers had stayed with their after-sales service strategy between 1997 and 2001 (0 of 37) and from 2001 to 2004 (0 of 41). In the second period, 5 of 41 after-sales service 
JOSM
21,1

Table IV.

Service strategy changes of the sample firms

120

\section{7}

Cluster 1: $n=60$

Customer service

strategy

Cluster $2: n=37$

After-sales service strategy

\section{1}

Cluster 1: $n=19$

Customer service strategy

Cluster 2: $n=41$

After-sales service strategy

Cluster 3: $n=37$ Customer-support service strategy

$\begin{array}{ccc} & & 2001 \\ \text { Cluster 1: } & \text { Cluster 2: } & \text { Cluster 3: } \\ \mathrm{n}=19 & \mathrm{n}=41 & \mathrm{n}=37 \\ \text { Customer service } & \text { After-sales service } & \text { Customer-support } \\ \text { strategy } & \text { strategy } & \text { service strategy } \\ 19(19.6 \%) & 41(42.3 \%)^{\mathrm{a}} & 0\end{array}$

0

0

$37(38.1 \%)^{\mathrm{b}}$

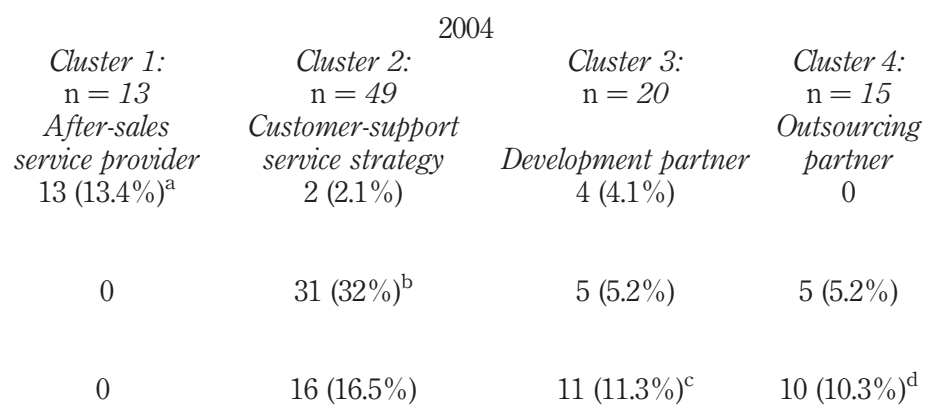

Notes: ${ }^{\text {aPattern } 1 ;}{ }^{\mathrm{b}}$ pattern 2; ${ }^{\mathrm{c}}$ pattern 3; ${ }^{\mathrm{d}}$ pattern 4

providers continued to move into the provision of R\&D-oriented services and position themselves as development partners. The emphasis of development partners on maintenance services suggests that the prevalent path sequence is to continue from being after-sales service providers and customer-support service providers to becoming development partners.

Consequently, the third pattern captures the strategic intent to move from customer-support service provider to development partners. Finally, the fourth pattern refers to the strategic change from customer-support service provider to outsourcing partner. The dominating patterns from customer-support service providers towards other service strategies such as development partner and outsourcing partner, however, become less clear. The ratio of ten of 37 firms moving from customer-support service strategy to operational services is similar to 11 of 37 companies moving from customer-support services to R\&D-oriented services. Five companies, however, moved from after-sales service provider to development partner. The substantial emphasis of development partners on offering maintenance services suggests that these five companies might also have positioned themselves as customer-support service providers. Five companies positioned as after-sales service providers also continued towards operational services.

As illustrated in Table IV, our findings indicate four dominant patterns of service strategy changes: 
(1) from customer service strategy to after-sales service provider;

(2) from after-sales service provider to customer-support service provider;

(3) from customer-support service provider to development partner; and

(4) from customer-support service provider to outsourcing partner.

The implications of these four patterns of service strategy changes for the organizational design elements are discussed in the next section.

Results of the qualitative research

The results of the 15 case studies obtained in 1997, 2001, and 2004 indicate a specific alignment among the four patterns of service strategy change and nine organizational design elements. More specifically, each pattern of service strategy change corresponds with specific modifications among the following: corporate values, employee behavior, personnel recruitment, personnel training, personnel assessment/compensation, organizational distinctiveness between products and services, proximity to customers, formality of service development process, and customer involvement in the service development process.

Because of the exploratory nature of this research, propositions rather than formal descriptions of the findings have been developed. We summarize the interrelationship between service strategy changes and modifications in organizational design elements by presenting sets of propositions listed in Table V. Each pattern of service strategy change and its corresponding set of propositions are discussed in the following paragraphs. By changing the service strategy from customer service strategy to after-sales service provider strategy, modifications in corporate values and employee behavior are strongly required. In addition, this pattern of change in service strategy places average emphasis on the distinction between product and service organization. Other organizational design elements are of incremental relevance for changing from providing customer service to after-sales services.

This first pattern of service strategy change corresponds with a limited number of modifications in the organizational design elements, whereas the second pattern requires a broad set of organizational modifications. The second pattern corresponds with the first pattern with the increase of service orientation in corporate values and employee behavior. In addition, the second pattern places more emphasis on service orientation in personnel training and personnel compensation/assessment, organizational distinctiveness, proximity to customers and formality of the service development process. All other organizational design elements seem to be of little importance for implementing the second pattern of service strategy change.

The third pattern of service strategy change requires modifications mainly in the service orientation of corporate values, employee behavior, personnel recruitment, personnel training, and customer involvement in the service development process. In contrast, relatively little emphasis is placed on the other organizational design elements such as personnel assessment/compensation, organizational distinctiveness, proximity to customers, and formality of the service development process.

Finally, the fourth pattern of service strategy change from the customer-support service strategy to the outsourcing partner strategy has been implemented by five of the 15 case studies. The alignment of this pattern of service strategy change requires a strong emphasis on organizational distinctiveness between products and

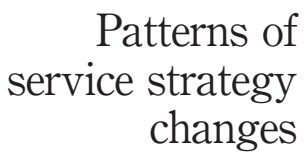

121 


\section{JOSM 21,1}

122

The implementation of Pattern 1, from customer service provider to after-sales service provider [...] $P 1 \quad$ It is strongly associated with an increase of the service orientation of organizational design elements related to corporate culture (corporate values and employee behavior)

P2 It is moderately associated with an increase of the organizational distinctiveness between product and services

P3 It is interrelated only little with organizational design elements related to human resource management (personnel recruitment, training and assessment/compensation), service development (customer involvement in and formality of the service development process) and proximity to customers

The implementation of Pattern 2, from after-sales service provider to customer-support service provider [...]

P4 It is associated with an increase of the service orientation of corporate culture (corporate values and employee behavior), organizational structure (organizational distinctiveness and proximity to customers), personnel training, personnel compensation/assessment, and of the formality of the service development process

P5 It is interrelated only little with personnel recruitment and customer involvement in the service development process

The implementation of Pattern 3, from customer-support service provider to development partner [...]

P6 It is associated with an increase of the service orientation of corporate culture (corporate values and employee behavior), personnel recruitment, personnel training, and of customer involvement in the service development process

P7 It is interrelated only little with personnel assessment/compensation, organizational structure (organizational distinctiveness and proximity to customers), and formality of the service development process

The implementation of Pattern 4, from customer-support service provider to outsourcing partner [...] P8 It is strongly associated with an increase of the service orientation of organizational structure (organizational distinctiveness between products and services and proximity to customers)

Table V.

Propositions to modify organizational design elements when changing the service strategy
P9 It is moderately associated with an increase of customer involvement in the service development process and the service orientation of employee behavior and personnel assessment/compensation

P10 It is interrelated only little with corporate values, personnel recruitment, personnel training, and formality of the service development process

services as well as on proximity to customers. Furthermore, whereas customer involvement in the service development process, employee behavior, and personnel assessment/compensation are of average importance for moving towards the outsourcing partner strategy, other elements such as corporate values, personnel recruitment, personnel training, and formality of the service development process are of incremental importance. To summarize the observations previously mentioned, we organized the key organizational modifications as propositional statements in Table V.

\section{Discussion}

\section{Theory replication and extension}

This study identifies patterns of service strategy changes and highlights how these patterns correspond with modifications in organizational design elements. Our findings replicate and extent existing theory.

Whereas, the findings on the five service strategies replicate the existing literature on service strategy and offerings (Davies, 2004; Gebauer, 2008; Mathieu, 2001b; Oliva 
and Kallenberg, 2003), the four patterns of service strategy changes extend existing theory. These four patterns suggest that the transition of manufacturing companies into service provision can be translated situationally into different service strategies. The four patterns represent different avenues for developing service strategies in a manufacturing company.

Furthermore, the four patterns indicate that the service strategies are unstable. Customer service strategy and after-sales service strategy are no longer a potential means of achieving competitive advantage. Manufacturing firms must move further towards the strategic position of customer-support service provider, development partner or outsourcing partner. A similar argument applies to the customer-support service strategy, because companies move from that position towards development partner and outsourcing partner. Another interesting extension of the existing theory on service and manufacturing strategies (Bowen and Ford, 2002) lies in the absence of reverse paths among service strategies. Cagliano et al. (2005) describe the change from one manufacturing strategy to another where companies can also adopt the reverse path. Interestingly, the directions of four indicated patterns of service strategy changes suggest that reverse paths seem nonexistent in service strategies.

Prevalent patterns among service strategy changes differ from the existing literature. Oliva and Kallenberg (2003) argue that companies that have entered the market for the installed base continue the transition from products to services by equally expanding the relationship- and process-oriented services. The results of this study suggest that after-sales service providers implement Pattern 2 and continue to move towards the customer-support service strategy. After implementing the customer-support service strategy, the companies proceed either with Patterns 3 or 4 towards the position of outsourcing, or as a development partner. Overall, the findings suggest that companies can change their service strategy relatively easily. Change in service strategies, in other words, has become a part of daily business. Strategic flexibility in service business is emerging as a key characteristic.

The third and major contribution links patterns of service strategy changes to modifications in organizational design elements. This study highlights the relative importance of different organizational design elements for each pattern of service strategy change. Existing research mainly describes the alignment of organizational design elements with manufacturing companies moving towards service and/or solution provision on a general level (Galbraith, 2002; Gebauer et al., 2005; Oliva and Kallenberg, 2003; Neu and Brown, 2005, 2008). Instead of arguing that service strategies require an increase in service orientation in all organizational design elements, we offer a complementary perspective. We propose that each pattern of service strategy change requires the alignment of a limited number of organizational design elements.

An interesting example of an insight into the modification of organizational design elements is the discussion about whether companies should integrate or separate the product and the service business. Whereas, Neu and Brown (2005) argue that companies should integrate business responsibilities for the product and service business, Oliva and Kallenberg (2003) propose that a separation of the service business facilitates the transition from the product to the service business. Our findings suggest that Patterns 1, 2, and 4 require an increased distinction between product and service business. For implementing Pattern 3, however, the level of distinctiveness between 
JOSM 21,1 products and services remains relatively low, leading to the assumption that R\&D-oriented services are emphasized by integrated business unit responsibilities.

\section{Managerial implications}

The patterns of service strategy changes provide guidance for managers seeking new strategic opportunities. Manufacturing companies concentrating on customer service strategies lose the potential to differentiate their product through customer services. Considering Levitt's (1972) challenging statement that everyone is in the service business, differentiation through customer service is extremely difficult. The statement also seems to be increasingly applicable to basic services for the installed base. Managers must realize that the position of after-sales service strategy is unstable, but is evolving into a customer-support service strategy.

Our set of propositions presented in Table $\mathrm{V}$ can serve as a managerial navigator, indicating which organizational design elements are associated with each pattern of service strategy change. Managers considering a movement from the after-sales service strategy to customer-support service strategy, for example, should emphasize a broad range of organizational design elements such as the following: formality in the service development process, service orientation in corporate values and employee behavior, service orientation of personnel training and personnel assessment/compensation, organizational distinctiveness, and proximity to customers. In contrast, the third pattern of service strategy change suggests concentrating on a narrower set of organizational design elements. These organizational design elements include customer involvement in the service development process, service orientation in corporate values and employee behavior, and service orientation of personnel recruitment and training. The propositions offer managerial guidance for investments in organizational design elements. This guidance might also help to overcome the formerly mentioned service paradox, where companies invest in the service business, but do not create the expected corresponding returns.

\section{Limitations and future research}

The main limitation of this study is the purposive sampling. Only companies with above average performance in service business were selected and this study concentrates on companies that succeeded in formulating and implementing service strategies. Thus, the first logical direction of future research would be the development and exploration of companies struggling with achieving successful service performance. The integration of less-successful companies would facilitate the development of a more precise and detailed theory on patterns of change in service strategies. Another limitation concerns the drivers of change from one service strategy to another. Is the strategic move from customer service strategy to after-sales service strategy, for example, a result of a deliberate strategic choice driven by strategic, financial or marketing opportunities? In other words, future research should explore key factors behind the changes in service strategies more thoroughly. Knowledge about these key factors would also help to clarify why reverse paths seem nonexistent among service strategies.

Another limitation arises around the longitudinal study. Owing to the long observation period of our longitudinal study, the research design was not considered entirely rigid throughout the study but rather flexible to include necessary adaptations 
over time such as evolving the conceptual research framework or revising interview guides to capture new developments and reflect progress in the literature. The development of the conceptual framework was in the beginning mainly based on early German-speaking literature on industrial services and organizational design elements in a service context (Simon, 1993; Noch, 1995; Homburg and Garbe, 1996; Belz et al., 1997; Lay, 1998). Over time, we adapted the framework to include the latest literature (Galbraith, 2002; Mathieu, 2001b; Oliva and Kallenberg, 2003; Homburg et al., 2003; Neu and Brown, 2005). However, in our paper we focused on the main references only.

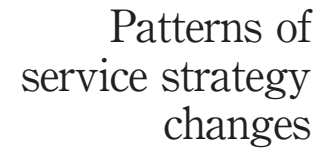

125 To clarify the development of the conceptual framework, we included some of the earlier German-speaking literature in the paper.

Furthermore, the study is limited through the lack of assessment in external validity. Future studies should follow Reinartz et al.'s (2004) suggestion on assessing external validity through multiple indicators and multiple causes models. A satisfactory approach to validation, while allowing the assessment of the proposed indicators and formative scales for service strategies as a set, is to link the indexes to another reasonable construct and estimate a multiple indicator and a multiple cause model (Diamantopoulos et al., 2008). Validation along these lines requires:

- that information be gathered for at least one more construct than the one captured by the indexes;

- that this other construct is measured by means of reflective indicators; and

- that a theoretical relationship can be postulated to exist between the constructs (Diamantopoulos and Winklhofer, 2001).

We recommend using the service strategies as predictors of service differentiation. Service differentiation could be assessed by the degree of service differentiation, new service development and price level of services (Kim and Lim, 1988; Dess and Davis, 1984).

The final limitation of the study stems from the limited number and aggregated nature of organizational design elements. By focusing on nine organizational design elements, we have neglected to explain in detail the necessary triggers and actions for implementing these elements. We consider these triggers and actions to be beyond the scope of this paper. Our objective was merely to explain the organizational design elements relevant for each pattern of service strategy change. We indicated nine elements that differ in their importance for patterns of service strategy changes. There are other organizational elements, but the nine that we described capture the main challenges inherent in implementing service strategy changes. Nevertheless, we strongly recommend using a more comprehensive model of organizational design elements for future studies.

\section{References}

Antioco, M., Moenaert, R.K., Lindgreen, A. and Wetzels, M. (2008), "Organizational antecedents to and consequences of service business orientations in manufacturing companies", Journal of the Academy of Marketing Science, Vol. 36 No. 3, pp. 337-58.

Belz, C., Schuh, G., Groos, A. and Reinecke, S. (1997), Industrie als Dienstleister, Thexis, St Gallen.

Bollen, K.A. and Lennox, R. (1991), "Conventional wisdom on measurement: a structural equation perspective”, Psychological Bulletin, Vol. 110 No. 2, pp. 305-14. 
JOSM 21,1
Bowen, D.E., Siehl, C. and Schneider, B. (1989), "A framework for analyzing customer service orientations in manufacturing", Academy of Management Review, Vol. 14 No. 1, pp. 75-95.

Bowen, J. (1990), "Development of a taxonomy of services to gain strategic marketing insights", Journal of the Academy of Marketing Science, Vol. 18 No. 1, pp. 43-9.

Bowen, J. and Ford, R.C. (2002), "Managing service organizations: does having a 'thing' make a difference?”, Journal of Management, Vol. 28 No. 3, pp. 447-69.

Boyt, T. and Harvey, M. (1997), "Classification of industrial services - a model with strategic implications", Industrial Marketing Management, Vol. 26 No. 4, pp. 291-300.

Cagliano, R., Acur, N. and Boer, H. (2005), "Patterns of change in manufacturing strategy configurations", International Journal of Operations \& Production Management, Vol. 25 No. 7, pp. 701-18.

Davies, A. (2003), “Are firms moving 'downstream' into high-value services?”, in Tidd, J. and Hull, F.M. (Eds), Service Innovation, Series on Technology Management, Vol. 9, Imperial College Press, London, pp. 21-34.

Davies, A. (2004), "Moving base into high-value integrated solutions: a value stream approach", Industrial and Corporate Change, Vol. 13 No. 5, pp. 727-56.

Davies, A., Brady, T. and Hobday, M. (2007), "Organizing for solutions: systems seller vs systems integrator”, Industrial Marketing Management, Vol. 36 No. 2, pp. 183-93.

Dess, G. and Davis, P.S. (1984), "Porter's (1980) generic strategies as determinants of strategic group membership and organizational performance", The Academy of Management Journal, Vol. 27 No. 3, pp. 467-88.

Diamantopoulos, A. and Winklhofer, H.M. (2001), "Index construction with formative indicators: an alternative to scale development", Journal of Marketing Research, Vol. 38 No. 2, pp. 269-77.

Diamantopoulos, A., Riefler, P. and Roth, K.P. (2008), "Advancing formative measurement models”, Journal of Business Research, Vol. 61 No. 12, pp. 1203-18.

Eisenhardt, K.M. (1989), "Building theories from case study research”, Academy of Management Review, Vol. 14 No. 4, pp. 532-50.

Frohlich, M.T. and Dixon, J.R. (2001), "A taxonomy of manufacturing strategies revisited", Journal of Operations Management, Vol. 19 No. 5, pp. 541-58.

Galbraith, J.R. (2002), “Organizing to deliver solutions”, Organizational Dynamics, Vol. 31 No. 2, pp. 194-207.

Gebauer, H. (2008), "Identifying service strategies in product manufacturing companies by exploring environment-strategy configurations", Industrial Marketing Management, Vol. 37 No. 3, pp. 278-91.

Gebauer, H., Fleisch, E. and Friedli, T. (2005), "Overcoming the service paradox in manufacturing companies”, European Management Journal, Vol. 23 No. 1, pp. 14-26.

Gummesson, E. (1994), "Service management: an evaluation and the future", International Journal of Service Industry Management, Vol. 5 No. 1, pp. 77-96.

Homburg, C. and Garbe, B. (1996), "Industrielle Dienstleistungen - Bestandsaufnahme und Entwicklungsrichtungen”, Zeitschrift für Betriebswirtschaft, Vol. 66 No. 3, pp. 253-82.

Homburg, C., Fassnacht, M. and Guenther, C. (2003), "The role of soft factors in implementing a service-oriented strategy in industrial marketing companies", Journal of Business-to-Business Marketing, Vol. 10 No. 2, pp. 23-51. 
Homburg, C., Hoyer, W. and Fassnacht, M. (2002), "Service orientation of a retailer's business strategy: dimensions, antecedents, and performance outcomes", Journal of Marketing, Vol. 66 No. 4, pp. 86-101.

Homburg, C., Workman, J.P. and Jensen, O. (2000), "Fundamental changes in marketing organization: the movement toward a customer-focused organizational structure", Journal of the Academy of Marketing Science, Vol. 28 No. 4, pp. 459-78.

Homburg, C., Workman, J.P. and Krohmer, H. (1999), "Marketing's influence within the firm", Journal of Marketing, Vol. 63 No. 2, pp. 1-17.

Johnstone, S., Dainty, A. and Wilkinson, A. (2008), "In search of 'product-service': evidence from aerospace, construction, and engineering", The Service Industries Journal, Vol. 26 No. 6, pp. 1-14.

Kellogg, D.L. and Nie, W. (1995), “A framework for strategic service management”, Journal of Operations Management, Vol. 13 No. 4, pp. 323-37.

Ketchen, D.J. Jr and Shook, C.L. (1996), "The application of cluster analysis in strategic management research", Strategic Management Journal, Vol. 17 No. 6, pp. 441-58.

Kim, L. and Lim, Y. (1988), "Environment, generic strategies, and performance in a rapidly developing country: a taxonomic approach", The Academy of Management Journal, Vol. 31 No. 4, pp. 802-27.

Kotler, P. (1994), Marketing Management: Analysis, Planning, Implementation and Control, 8th ed., Prentice-Hall, Englewood Cliffs, NJ.

Kumar, N., Stern, L.W. and Anderson, J.C. (1993), "Conducting inter-organizational research using key informants”, Academy of Management Journal, Vol. 36 No. 6, pp. 1633-51.

Kumar, R., Markeset, T. and Kumar, U. (2004), "Maintenance of machinery: negotiating service contracts in business-to-business marketing", International Journal of Service Industry Management, Vol. 15 Nos 3/4, pp. 400-13.

Kyj, L.S. and Kyj, M.J. (1989), "Customer service: product differentiation in international markets", International Journal of Physical Distribution \& Material Management, Vol. 19 No. 1 , pp. 30-8.

Lay, G. (1998), "Dienstleistungen in der Investitionsgüterindustrie - Konsequenzen für Betriebsorganisation und Personal", Arbeit, Vol. 7 No. 4, pp. 316-37.

Levitt, T. (1972), "Production-line approach to service", Harvard Business Review, Vol. 50 No. 5, pp. 41-52.

Lovelock, C. (1994), Product Plus: How Product+Service=Competitive Advantage, McGraw-Hill, New York, NY.

Martin, C.R. Jr and Horne, D.A. (1992), "Restructuring towards a service orientation: the strategic challenges", International Journal of Service Industry Management, Vol. 3 No. 1, pp. 25-38.

Mathe, H. and Shapiro, R.D. (1993), Integrating Service Strategy in the Manufacturing Company, Chapman \& Hall, London.

Mathieu, V. (2001a), "Product services: from a service supporting the product to a service supporting the client”, Journal of Business \& Industrial Marketing, Vol. 16 No. 1, pp. 39-58.

Mathieu, V. (2001b), "Service strategies within the manufacturing sector: benefits, costs and partnership", International Journal of Service Industry Management, Vol. 12 No. 5, pp. 451-75.

Matthyssens, P. and Vandenbempt, K. (1998), "Creating competition advantage in industrial services”, Journal of Business \& Industrial Marketing, Vol. 13 Nos 4/5, pp. 339-55. 
JOSM 21,1
Miles, M.B. and Huberman, A.M. (1994), Qualitative Data Analysis: An Expanded Sourcebook, 2nd ed., Sage, Thousand Oaks, CA.

Miller, J.G. and Roth, A.V. (1994), "Taxonomy of manufacturing strategies", Management Science, Vol. 40 No. 3, pp. 285-304.

Mintzberg, H. and Quinn, J. (1988), The Strategy Process, Prentice-Hall, Harlow, p. 1988.

Morrison, A.J. and Roth, K. (1992), "A taxonomy of business-level strategies in global industries", Strategic Management Journal, Vol. 13 No. 6, pp. 399-417.

Neu, W.A. and Brown, S.W. (2005), "Forming successful business-to-business services in goods-dominant firms", Journal of Service Research, Vol. 8 No. 1, pp. 3-17.

Neu, W.A. and Brown, S.W. (2008), "Manufacturers forming successful complex business services: designing an organization to fit the market", International Journal of Service Industry Management, Vol. 19 No. 2, pp. 232-51.

Noch, R. (1995), Dienstleistungen im Investitionsgüter-Marketing - Strategien und Umsetzung, FGM, München.

Oliva, R. and Kallenberg, R. (2003), "Managing the transition from products to services", International Journal of Service Industry Management, Vol. 14 No. 2, pp. 160-72.

Parasuraman, A. (1998), "Customer service in business-to-business markets: an agenda for research”, Journal of Business \& Industrial Marketing, Vol. 13 Nos 4/5, pp. 309-21.

Patton, M.Q. (1990), Qualitative Evaluation and Research Methods, 2nd ed., Sage, Newbury Park, CA.

Phillips, L.W. (1981), “Assessing measurement error in informant reports: a methodological note on organizational analysis in marketing”, Journal of Marketing Research, Vol. 18 No. 4, pp. 395-415.

Punj, G. and Stewart, D.W. (1983), "Cluster analysis in marketing research: review and suggestions for application”, Journal of Marketing Research, Vol. 20 No. 2, pp. 134-48.

Reinartz, W., Krafft, M. and Hoyer, W.D. (2004), "The customer relationship management process: its measurement and impact on performance", Journal of Marketing Research, Vol. 41 No. 3, pp. 293-305.

Schuh, G., Friedli, T. and Gebauer, H. (2004), Fit for Service - Industrie als Dienstleister, Hanser, Munich.

Simon, H. (1992), "Service policies of German manufacturers - critical factors in international competition”, European Management Journal, Vol. 10 No. 4, pp. 404-11.

Simon, H. (1993), Industrielle Dienstleistungen, Schäffer-Poeschel, Stuttgart.

Strauss, A.L. (1987), Qualitative Analysis for Social Scientists, Cambridge University Press, Cambridge.

Strauss, A.L. and Corbin, J.M. (1998), Basics of Qualitative Research: Techniques and Procedures for Developing Grounded Theory, Sage, Thousand Oaks, CA.

Vandermerwe, S. and Rada, J. (1988), "Servitization of business: adding value by adding services”, European Management Journal, Vol. 6 No. 4, pp. 314-24.

Wise, R. and Baumgartner, P. (1999), "Go downstream: the new imperative in manufacturing", Harvard Business Review, Vol. 77 No. 5, pp. 133-41.

Yin, R.K. (1994), Case Study Research: Design and Methods, 2nd ed., Sage, London. 


\section{Further reading}

Gebauer, H. and Fleisch, E. (2007), "An investigation of the relationship between behavioral processes, motivation, investments in the service business and service revenue", Industrial Marketing Management, Vol. 36 No. 3, pp. 337-48.

Gebauer, H., Friedli, T. and Fleisch, E. (2006), "Success factor for achieving high service revenues in manufacturing companies", Benchmarking: An International Journal, Vol. 13 No. 3, pp. 374-86.

\section{Corresponding author}

Heiko Gebauer can be contacted at: heiko.gebauer@unisg.ch
Patterns of service strategy changes

129

To purchase reprints of this article please e-mail: reprints@emeraldinsight.com Or visit our web site for further details: www.emeraldinsight.com/reprints 